\title{
Phenomenological Optimization of Weekly Integrated Collider Luminosity
}

\author{
Alan Hahn \\ Fermi National Accelerator Laboratory \\ P.O. Box 500, Batavia, Illinois 60510
}

March 1994 


\section{Disclaimer}

This report was prepared as an account of work sponsored by an agency of the United States Government. Neither the United States Government nor any agency thereof, nor any of their employees, makes any warranty, express or implied, or assumes any legal liability or responsibility for the accuracy, completeness, or usefulness of any information, apparatus, product, or process disclosed, or represents that its use would not infringe privately owned rights. Reference herein to any specific commercial product, process, or service by trade name, trademark, manufacturer, or otherwise, does not necessarily constitute or imply its endorsement, recommendation, or favoring by the United States Government or any agency thereof. The views and opinions of authors expressed herein do not necessarily state or reflect those of the United States Government or any agency thereof. 


\title{
TM\#
}

\section{Phenomenological Optimization of Weekly Integrated Collider Luminosity}

Alan Hahn

FNAL, AD/Instrumentation 3/3/94

\begin{abstract}
A model of the weekly integrated luminosity production is presented. It is shown that optimal weekly integrated luminosity production occurs with store lengths greater than 20 hours.
\end{abstract}

\section{Introduction:}

This model was made in response to requests in early 1993 from the collider experiments for a justification of the length in which a store was intentionally left in the Tevatron. In some respects, the results were surprising, but found to be sound. The model is entirely phenomenological in all its aspects. Perhaps a sound theoretical model might in some future time be found, but for now this simple approach, if reasonably applied will achieve sound results.

The central tenet of the model is that the only parameter under the control of the "Collider Coordinator" is the store length i.e. the time that luminosity is delivered to the collider experiments. All other effects, although extremely important, are almost completely out of his/her control. These other parameters are fit to simple functions which reflect at the time of this calculation, a reasonable approximation of reality.

\section{Procedure:}

For the sake of comparison to reality, this model was normalized to Store \#4112 (Fig. 1). Store $4112 \mathrm{had}$, at low beta, an average (proton/pbar) intensity of (141/42) e9/bunch, an average (proton/pbar) emittance of $(18.5 / 16.2) \pi \mathrm{mm}-\mathrm{mr}$, and an initial luminosity of $7.35 \mathrm{e} 30 / \mathrm{sec}$. That shot was from a stack of $89.7 \mathrm{~mA}$. The integrated store luminosity was $285 \mathrm{nb}^{-1}$, the best total at that time. The store lifetime was initially 10.4 hours, growing by $0.36 \mathrm{hr}$ per hour. 
Fig. 1: Fit of B0 Luminosity for store 4122

$$
\text { - }- \text { - BOLumV (e30/s) }
$$

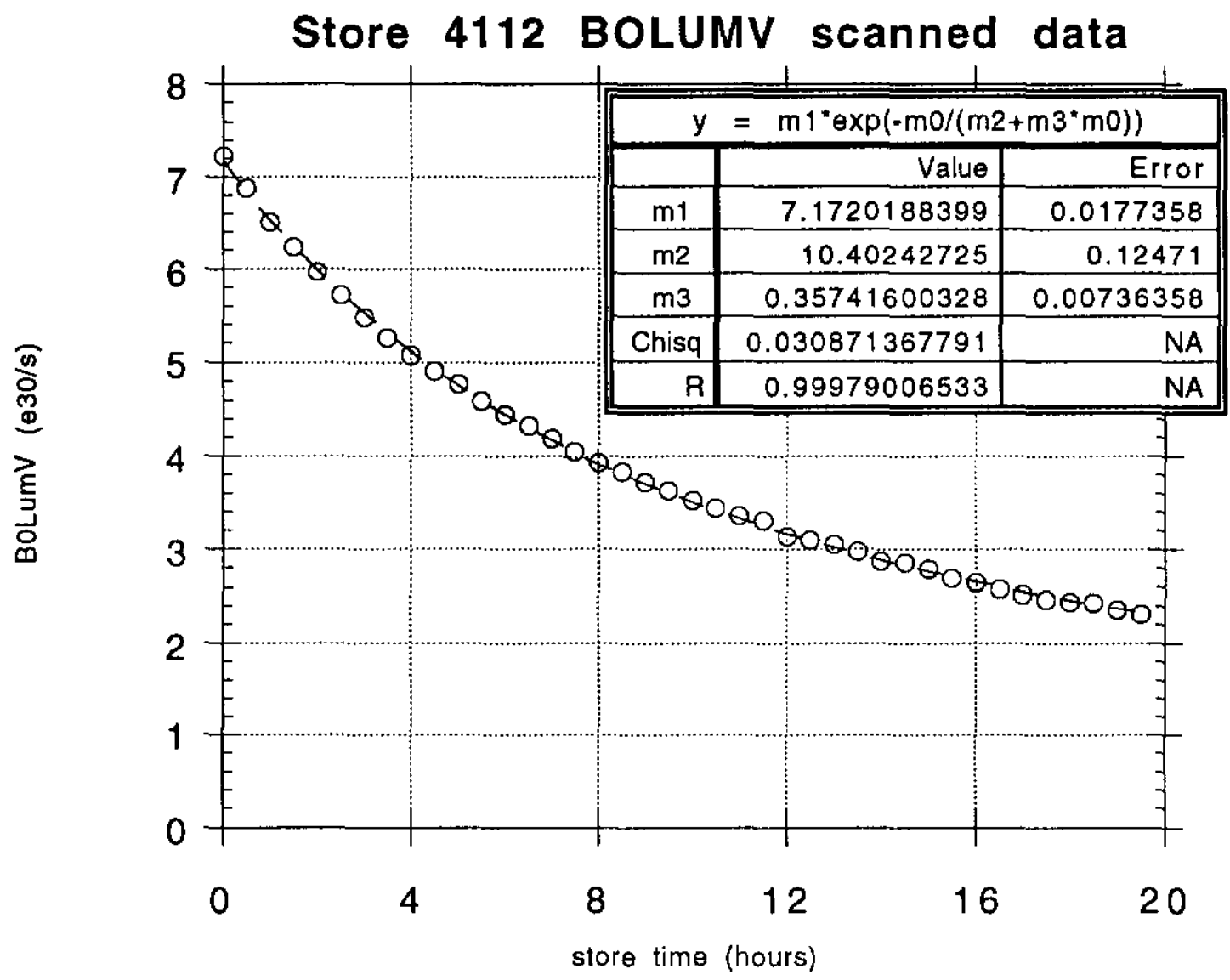

The weekly integrated luminosity can be written as

$$
L^{\text {week }}=\frac{168 \mathrm{hrs}}{\left(\Delta t_{\text {store }}+\Delta t_{\text {setup }}\right)} \int_{0}^{\Delta t_{\text {store }}} L(t) d t
$$

with the instantaneous luminosity at time $t$ in the store

$$
L(t)=L_{0} e^{-\left(\frac{t}{\tau_{\text {store }}+\mu t}\right)} .
$$

$L_{0}=\frac{L_{0}^{4112}}{N_{\bar{p}}^{e q u i}}$ is the initial Luminosity (normalized to store 4112 ), $\tau_{\text {store }}$ is the initial store lifetime, and $\mu$ the lifetime growth in $\mathrm{hr} / \mathrm{hr}$. 
$N_{\bar{p}}^{e q u i}$ is the equilibrium (actually steady state) value of the number of pbars at low beta once the stores have equal lengths. Using data from runs $3808-4190, \quad N_{\bar{p}}^{e q u i}$ can be written as a function of the equilibrium stack,

$$
\begin{aligned}
N_{\bar{p}}^{\text {equi }}= & 0.498 * \operatorname{Stack}_{\text {equi }}\left(\Delta t_{\text {store }}, \sigma_{0}, \tau_{\text {stack }}, f r\right)- \\
& 0.000551 *\left(\operatorname{Stack}_{\text {equi }}\left(\Delta t_{\text {store }}, \sigma_{0}, \tau_{\text {stack }}, f r\right)\right)^{2}
\end{aligned}
$$

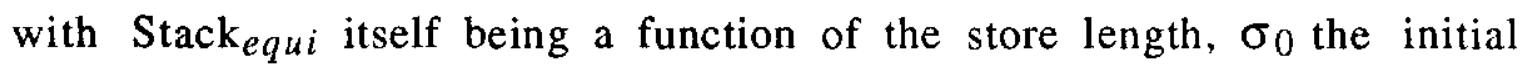
stacking rate at zero stack, $\tau_{\text {stack }}$ the stack lifetime, and $f r$ the fraction remaining of the stack after a shot. The range of validity of this equation is good for stacks up to $200 \mathrm{~mA}$ (or store lengths less than 50 hours). A reasonable fit of $f r$ is

$$
f r(\text { stack })=e^{-\frac{s t a c k}{\left(36.2+0.957^{*} \text { stack }\right)}}
$$

However in the model that follows, fr was taken to be 0.5 .

Solving the differential equation $\frac{d \text { stack }}{d t}=\sigma_{0}-\frac{\text { stack }}{\tau_{\text {stack }}}$ gives,

$$
\operatorname{Stack}(t)=\sigma_{0} \tau_{\text {stack }}\left(1-e^{\frac{-t}{\tau_{\text {stack }}}}\right)+\operatorname{Stack}(0) e^{\frac{-t}{\tau_{\text {stack }}}}
$$

For equilibrium conditions $\operatorname{Stack}(0)=f r * \operatorname{Stack}\left(\Delta t_{\text {store }}\right)$. Stacking and production efficiency data from Dec. 92 and Jan 93 (courtesy of E.Harms) support $\sigma_{0}=4 \mathrm{~mA} / \mathrm{hour}$, and $\tau_{\text {stack }}=50-100 \mathrm{hrs}$.

\section{Results :}

The weekly integrated luminosity is plotted as a function of store length for various values of the parameters. Unless otherwise stated, the assumed store (lifetime/lifetime growth) is $(10.4 \mathrm{hr} / 0.36 \mathrm{hr} / \mathrm{hr}$ ), the initial stacking rate $=3.5 \mathrm{~mA} / \mathrm{hr}$, and shot setup time $=2.5$ hours. 
Figure 2: Weekly Integrated Luminosity as a function of shot setup time $(0.5,1.5,2.5,3.5)$ hrs. The uppermost plot is 0.5 hours.

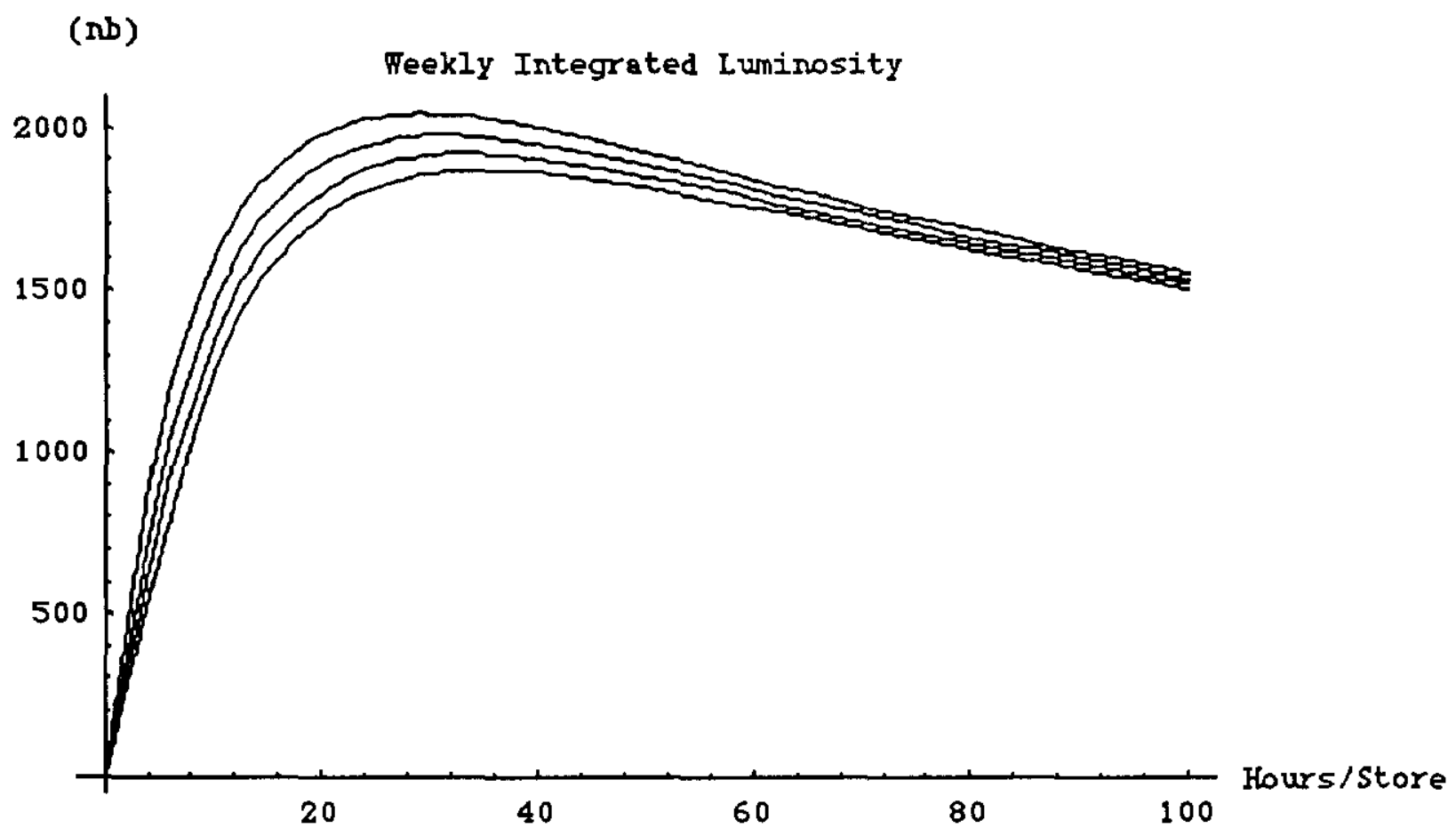

Figure 3: Weekly Integrated Luminosity for luminosity lifetime , $\tau_{\text {store }}=(5,10,15)$ hrs. The uppermost plot is for 15 hrs.

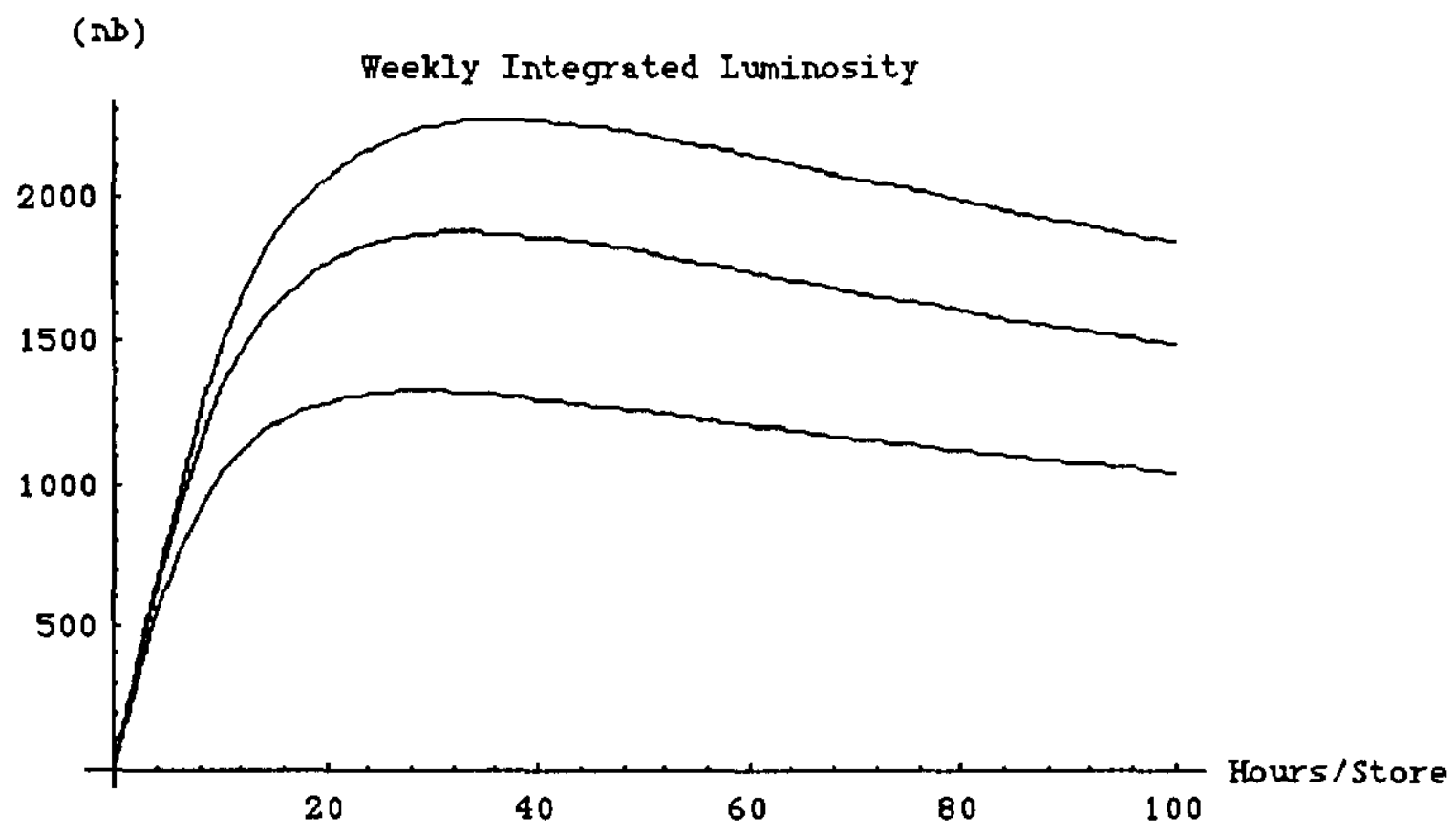


Figure 4: Weekly Integrated Luminosity for luminosity lifetime growth, $\mu=(0,0.1,0.2,0.3,0.4) \mathrm{hr} / \mathrm{hr}$. The uppermost plot is 0.4 $\mathrm{hr} / \mathrm{hr}$.

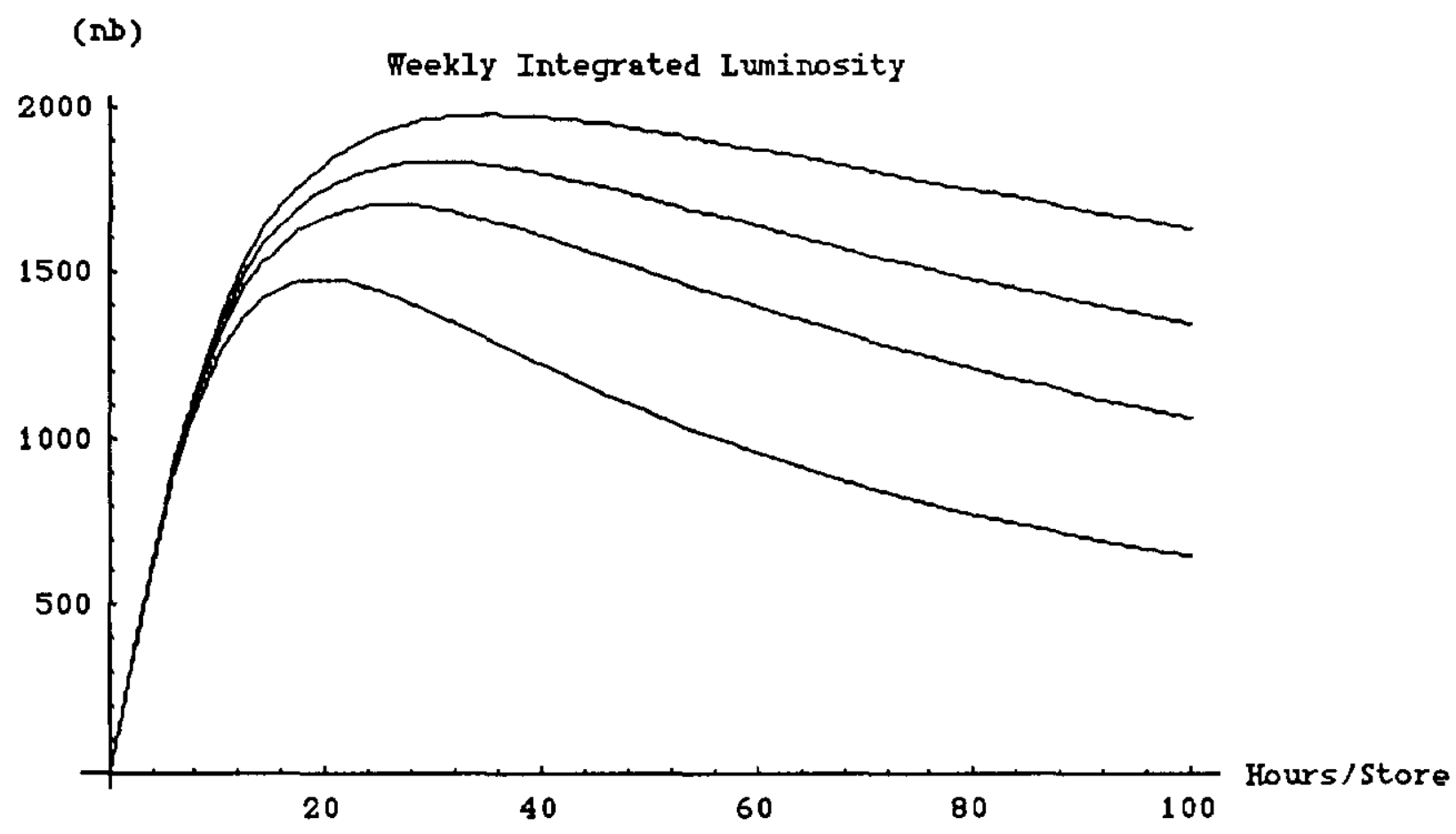

Figure 5: Weekly Integrated Luminosity for initial stacking rate, $\sigma_{0}=($ $2.5,3.5,4.5) \mathrm{mA} / \mathrm{hr}$. The uppermost plot is for $4.5 \mathrm{~mA} /$ hours.

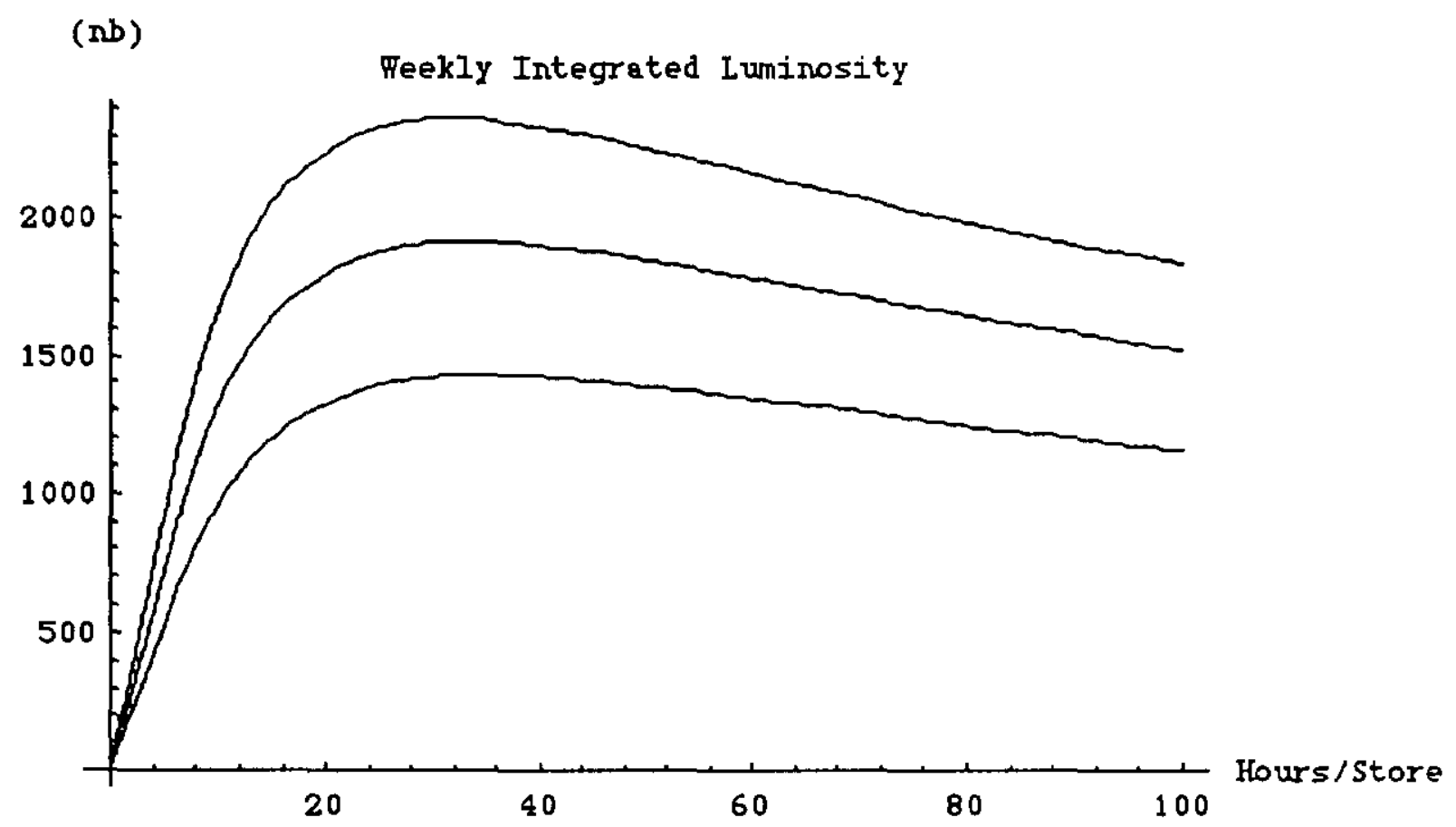


Figure 6: Weekly Integrated Luminosity for $\tau_{\text {stack }}=45,75,100 \mathrm{hrs}$. The uppermost plot is for 100 hours.

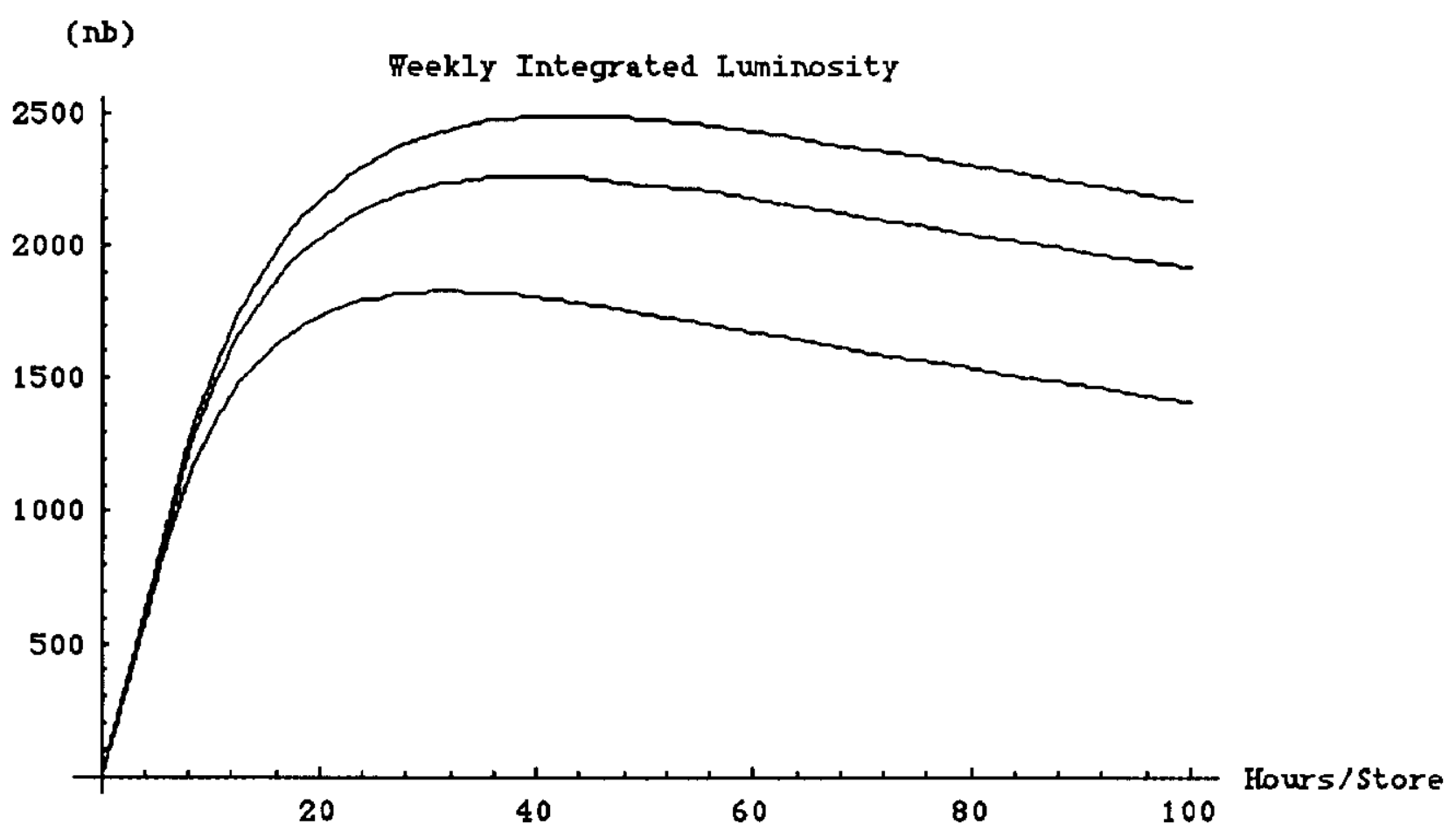

Figure 7: Equilibrium Initial Luminosity for initial stacking rate, $\sigma_{0}=$ $(2.5,3.5,4.5) \mathrm{mA} / \mathrm{hr}$. The uppermost plot is for $4.5 \mathrm{~mA} / \mathrm{hr}$.

Lo $(1 /(s-\mathrm{cm} 2))$

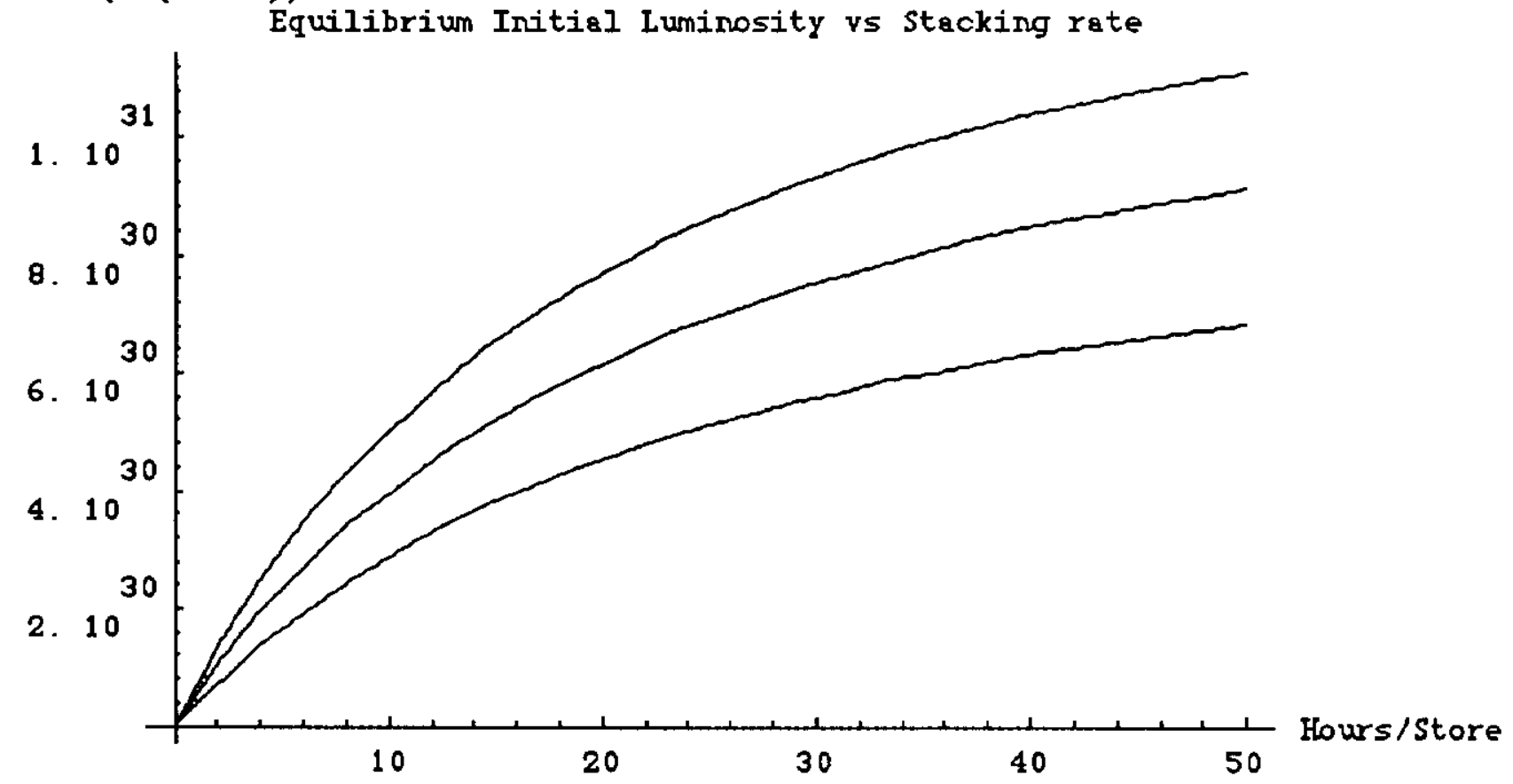


Figure 8. Equilibrium stack size for initial stacking rate, $\sigma_{0}=(2.5,3.5$, $4.5) \mathrm{mA} /$ hour.

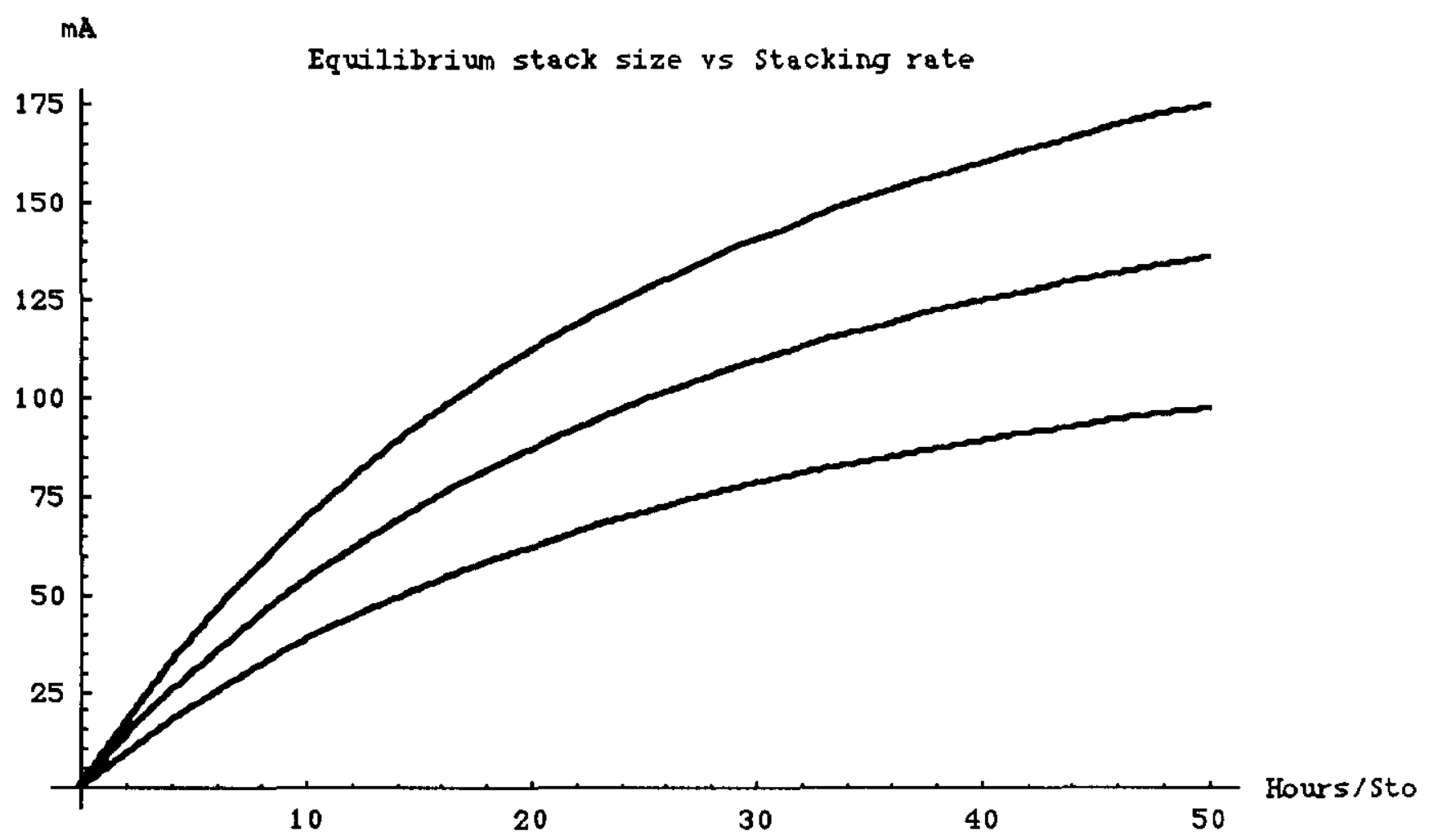

\section{Conclusions :}

It appears obvious from the above plots that in order to maximize luminosity, the store length should be at least 20 hours. Depending upon particular conditions, it perhaps should be as long as 30 hours. However the maximum is rather broad and thus is rather insensitive to "too long" stores. I am wary of my choice of functional forms for store times in excess of 50 hours, but since the integrated luminosity is dropping for all reasonable values of the parameters, I suspect that reality will only make things worse.

It has been often asked "But what do you do after the stack has been lost?". I think that the most obvious answer is to get to the optimum time the fastest, i.e. by having long stores even when the luminosity is as low as 3 e30. Psychologically it has been very difficult to keep the Collider experiments happy during this period, so at least when I was coordinator, I would try and make a shot at $50 \mathrm{~mA}$, wait 12 hours, then 16 hours, and then 20 hours or more. It was also asked "what about the adding a Monte Carlo "store lost" condition to the optimization procedure. My own viewpoint is that this is unnecessary. As long as the actual average store length continues to increase (as it did) as the intentional store length is 
increased, a random fault will not change the analysis. Long store lengths lead to generally large stacks which allow an early shot with high luminosity after a store loss, an insurance policy of sorts. Finally minimizing the number of shots seems like a good idea since during this time, one is at the mercy of the entire accelerator complex, leading to quite often, long shot setups. 